\title{
Measuring Usability of Phonic Mobile Applications based on User Success Rate for Pre-School Children
}

\author{
Carolyne Alphonsus Tommy', Jacey-Lynn Minoi \\ 'Institute of Social Informatics and Technological Innovations, Universiti Malaysia Sarawak, 94300 Kota Samarahan, Sarawak, Malaysia \\ ${ }^{2}$ Faculty of Computer Science and Information Technology, Universiti Malaysia Sarawak, 94300 Kota Samarahan, Sarawak, Malaysia
}

\begin{abstract}
Recent studies showed that mobile devices have the potential to support children's learning and have increased the interest of parents and educators. However, it is important that mobile applications for children are well-designed and usable to ensure the applications are effective for children learning. This study aims to look at the usability of mobile applications designed for pre-school children especially children with speech delay. We have conducted an experiment with 10 pre-school children with speech delay and eleven of $\mathrm{ABC}$ and phonics mobile applications were selected based on the prior studied guidelines. During the usability testing, children's behaviour and facial expression while playing mobile applications were observed and recorded. The collected data was measured using usability measurement by analysing user's success rate. Based on the result and analysis, children have showed positive expression towards the well-designed with good usability mobile application.
\end{abstract}

Keywords: Mobile Applications, Usability, Design Guidelines, Children.

\section{INTRODUCTION}

Mobile technologies have dramatically increased the accessibility and usage of technology among younger children. As children continue to become more immersed in media, learning using mobile devices can be used to support children's learning as they are easier to use and could provide fun and play ${ }^{1,2,3}$. Learning by using mobile technologies or commonly known as mobile learning in itself is not a new concept and these days, mobile capabilities have dramatically increased the interest of parents and educators. In general, children in this age range should be allowed to explore the computer or mobile technologies according to their own interests instead of performing manual or traditional of activities or tasks approaches.

Sutton and Olivier ${ }^{3}$ stated that various benefits could be gained when using mobile-based applications as the developed applications are exciting, less expensive, and more accessible and engaging resources compared to the paper-based assessment. As mobile apps could be access and use anywhere at any time, it represents a new resource available for anyone who tries to help children and adults to master literacy skills such as speech and other literacy learning difficulties with reading, spelling, and written expression and taking notes ${ }^{4}$.

However, a well-designed and good usability of mobile apps are very important to ensure the apps are effective for children learning. Research by Eshed ${ }^{5}$ has shown that both interface design and usability are the important factors in creating a better mobile learning. Poorly designed mobile apps for children with difficulties occurred when using the apps could affect their effective learning. This paper will discuss the usability of mobile apps designed for pre-school children based on the results gathered from usability testing that was conducted.

*Email Address: tommycarolyne@gmail.com 